\title{
LOS CONTRASTES Y LAS IRONÍAS \\ EN LA CIUDAD ALEGRE Y CONFIADA, DE JACINTO BENAVENTE
}

\section{CONTRASTS AND IRONIES IN LA CIUDAD ALEGRE Y CONFIADA BY JACINTO BENAVENTE}

\author{
Pol POPOVIC KARIC \\ Tecnológico de Monterrey, Campus Monterrey \\ pol.popovic@tec.mx
}

Resumen: Este trabajo propone un estudio sobre los contrastes y las ironías en La ciudad alegre y confiada de Jacinto Benavente. Estos tienen un impacto estilístico y cómico característicos del teatro español de las primeras décadas del siglo XX. Además, el contraste y la ironía definen la estructura ideológica de esta obra y justifican su cierre. En la primera sección, las características y los personajes individuales serán estudiados a través de las contradicciones e incoherencias sociales que contribuyen a la imprevisible naturaleza de la trama. En la segunda sección, el análisis de la estructura socioeconómica de la sociedad proveerá las bases para los conflictos individuales y colectivos. La última sección se enfocará en la relación entre la vida y la muerte. Los protagonistas Crispín y Desterrado están convencidos que la muerte es la única manera de purificar a la gente y de salvar su ciudad. Soren Kierkegaard, Wayne Booth and Peter Roster proveen los acercamientos teóricos a la ironía que se utilizarán en este trabajo.

Palabras clave: Teatro español. La ciudad alegre y confiada. Jacinto Benavente. Soren Kierkegaard. Wayne Booth. Peter Roster.

Abstract: This paper proposes a study of contrasts and ironies in Jacinto Benavente's play La ciudad alegre y confiada. They produce stylistic and comical effects that are typical of the Spanish drama in the first decades of the $20^{\text {th }}$ century. However, they also define the ideological structure of the 
play and justify its outcome. The contrasts and the ironies of this play will be studied in three sections. In the first one, the personal characteristics and roles will be examined. Their contradictions and incoherencies contribute to the unpredictable nature of the play. In the second section, the analysis of the socioeconomic structure of the society will provide the bases for individual and collective conflicts. The last section focuses on the relation between life and death. The key protagonists Crispin and Desterrado are convinced that death is the only way to purify the people and to save their town. Soren Kierkegaard, Wayne Booth and Peter Roster provide the theoretical approaches to irony that will be used in this study.

Key Words: Spanish theatre. La ciudad alegre y confiada. Jacinto Benavente. Soren Kierkegaard. Wayne Booth and Peter Roster.

\section{INTRODUCCIÓN}

El 18 de mayo de 1916, La ciudad alegre y confiada se estrenó en el Teatro Lara de Madrid bajo el ojo atento de su autor Jacinto Benavente (Benavente, 1907). Esta obra forma secuela con Los intereses creados, que fue estrenada nueve años antes, en el mismo teatro. En esta, se establece la relación entre los protagonistas Crispín y Leandro en la que se fundamentan la ética y el pragmatismo de esta representación. Gracias a Leandro, el auditorio presencia el despliegue de un amor idealista, mientras la ingeniosidad de Crispín permite a Leandro contraer matrimonio para liquidar sus deudas y salvar a ambos protagonistas de las galeras. La ciudad alegre y confiada cuenta con una visión más abarcadora de la sociedad que su antecesora. No se trata de una simple conquista amorosa ni de un ascenso socioeconómico de dos forasteros, sino de una colectiva bajada apocalíptica. Crispín lleva al pueblo a una guerra a sabiendas que esta ocasionará la muerte en masa. A diferencia de la lucha humanística por el amor y la libertad de la primera secuela, en La ciudad alegre y confiada surge el impulso de destrucción y auto-inmolación.

William Starkey y José Montero Alonso ubican La ciudad alegre y confiada en un período de transición de la época neorromántica a la realista durante las primeras décadas del siglo veinte (Starkey, 1924: 6770; Montero, 1967: 23). La grandilocuencia amorosa y la exuberancia 
pasional de los héroes románticos del siglo XIX ha bajado de tonalidad ostensiblemente y un lenguaje más realista ha surgido de las obras de Benavente. La finura de su lenguaje se ha ajustado a las nuevas normas del teatro europeo sin perder el gusto por la ingeniosidad y manifestaciones sentimentales representadas en el siglo anterior (Ballesteros, 2003: 182187).

La ciudad alegre y confiada dio continuidad y, a la vez, transformó el quehacer dramático de la Commedia dell'Arte que ha reinado en Europa durante tres siglos anteriores (Quezada, 1985: 57). Los personajes y ocasionalmente el vestuario de esta rica tradición italiana han sido parte de las representaciones de esta pieza de Jacinto Benavente. Crispín, Leandro, Silvia, Pantalón y Polichinela, entre otros personajes, comparten la naturaleza de sus antecesores italianos: incurren en diálogos conflictivos, manifiestan sus personalidades como la codicia o la ingeniosidad e inciden en comportamientos violentos (Monner, 1966: 90-91). Sin embargo, el requisito de templanza que se impuso con la entrada en el siglo veinte se refleja en los razonamientos basados en el realismo fundamentado en la corrupción, el poder económico y la crudeza de una derrota militar (Oliva, 2002: 60-63).

Gracias al lenguaje expresivo de Benavente y a una estructura dramática de adversidades complementarias, los contrastes y las ironías surgen con naturalidad en La ciudad alegre y confiada. Estos no tienen solo una función estética o cómica, también proveen las pautas para el despliegue de la trama y el desarrollo de las ideologías de sus personajes (Critchley, 2002: 91-97).

En tres secciones de este trabajo, se propone un análisis de los contrastes y de las ironías en La ciudad alegre y confiada. La primera ofrece perspectivas individuales de dos personajes, la segunda se enfoca en el contexto socioeconómico de la ciudad y la tercera provee un análisis de la relación entre la muerte y la existencia de los ciudadanos. Como referencias teóricas, se utilizarán los estudios sobra la ironía de Kierkegaard (1968: 290-322), Booth (1974: 32-60), Roster (1978: 41-43) y Sidgwick (1874: 107-110).

\section{PERSONAJES INDIVIDUALES}

En el espíritu de la Commedia dell'Arte, algunos personajes de 
Benavente se vuelven representantes de nociones contrarias (Preciado, 1990: 51), como la codicia y el desinterés, mientras otros encarnan los perfiles de distintos grupos sociales que promueven el statu quo o incitan a la población a la revolución. En esta sección, el hostelero y el Desterrado servirán de base para el análisis del contraste creado por estas temáticas.

En la primera escena de La ciudad alegre y confiada, el hostelero abre la brecha entre el pasado y el presente al rememorar su convivencia con Crispín y Leandro que se desarrolló en Los intereses creados. El hostelero describe su relación con estos como si hubiera sido marcada exclusivamente por el desinterés y nobles sentimientos: "[...] no olvidaron el desinterés con que les serví siempre” (Benavente, 1981: 162). Además, enfocándose en el presente de la representación, el hostelero se refiere a Crispín con halagos y sumo respeto: "Y hoy mismo, con ser quien es el señor Crispín, el Magnífico [...]” (Benavente, 1981: 163).

No obstante, el espectador de Los intereses creados se acordará que antes del enriquecimiento de Crispín y Leandro, el hostelero se había unido a sus acreedores para perseguirlos por incumplimiento de sus deudas. Sin embargo, esta fase de su relación con los protagonistas quedó borrada por el cambio en el estado financiero de estos y su generosa disposición de desembolsar cantidades considerables en la hostelería.

En A Rhetoric of Irony, Booth señala que las incongruencias y los contrastes a menudo indican la presencia de la ironía en una obra (Booth, 1974: 42). Este tipo de ironía, basada en la incongruencia, surge del contraste entre el recuerdo del espectador y las palabras del hostelero. La nueva interpretación de los eventos realizada por el hostelero borra lo indeseable y enfatiza lo deseable. La superposición de los contrarios da un aire cómico a la representación y recupera la tonalidad burlesca de la commedia dell'arte.

En la confluencia del olvido con la creación idealista del hostelero, también se manifiesta la ironía de Kierkegaard (1968: 290-322). En esta, la libertad absoluta se atribuye al individuo para que cancele la realidad y cree un mundo ideal. La libertad de Kierkegaard toma tres formas en esta representación dramática: el hostelero borra el pasado mentalmente, lo reconstruye verbalmente y lo utiliza de manera pragmática para tender lazos socioeconómicos con los poderosos de la ciudad.

Así, la representación escenifica el concepto teórico de Kierkegaard en tres niveles consecutivos: mental, verbal y actancial. Para que esta 
implementación de la visión filosófica ocurra en la representación dramática, la obra necesita la asistencia del espectador quien provee la perspectiva realista de los hechos que han tomado lugar en Los intereses creados. Sin el recuerdo del espectador, el hostelero no contaría con la realidad que necesita cancelar para dar forma a la ironía kierkegaardiana. Así, el espectador y su memoria contribuyen a la interpretación irónica del comportamiento del hostelero y lo preparan para los futuros enfrentamientos con distintos personajes e ideologías.

En ocasiones, la palabra del hostelero consolida sus relaciones personales con los poderosos de la ciudad y, en otras, lo defiende de los pobres. Su elocuencia le permitió atajar el impulso de sus mozos de criticar a los ricos y de quejarse de su condición de empleados. Al enfadarse, la palabra del hostelero pierde su tono melancólico y toma el carácter de imposición: “ßBasta de insolencia! Si no os conviene...” (Benavente, 1981: 163).

En este caso, el hostelero pinta el mundo con la subjetividad de la teoría de Kierkegaard y la protege con la autoridad que el dinero y su posición le conceden. Para cambiar la postura de los mozos, el hostelero da a su palabra un tono y un significado amenazantes. Su voz no solo plasma lo deseable, como en el caso de rememoración de su relación con Crispín y Leandro, sino también revoca lo indeseable. Aunque en ambos casos el propósito de los enunciados del hostelero consiste en la recreación de una realidad que lo favorece, sus palabras revelan dos aspectos contrastantes de su personalidad: la sumisión ante los ricos y la opresión de los pobres.

La ironía de Booth que enfatiza la presencia de los contrastes y la de Kierkegaard que empodera al ironista con la creación subjetivista de su entorno moldean la personalidad del hostelero y dan forma a su lucha. Su destreza en la inversión de los hechos le permite superar las adversidades y ubicarlo en lo más alto en la jerarquía social de la ciudad.

Peter Roster da a conocer su visión de la ironía y la describe como un producto de la desilusión que se manifiesta a través de un comentario breve en el que se usan las palabras cuyo significado literal contrasta con lo que el ironista desea expresar (Roster, 1978: 41-43). La amargura y el despecho forman el cuadro afectivo del que surge una ironía aguda y capaz de herir, pero sin quebrantar los protocolos sociales.

La recepción del Desterrado en la hostelería provee el ambiente idóneo para la representación escenográfica de la ironía de Roster. Al darse 
cuenta que el hostelero no es tan acogedor como en los tiempos anteriores a su destierro, el recién llegado finge aceptar su oferta de hospitalidad, "[...] yo no puedo desairar la cena que me has ofrecido" (Benavente, 1981: 183). Sin embargo, casi instantáneamente, se retira con su hijo para acudir a algún otro establecimiento.

La réplica del Desterrado surge de la amargura ocasionada por el desengaño. Recuerda la amabilidad del hostelero en otros tiempos que contrasta con la frialdad de su reencuentro y su amargura se oculta en el comentario "[...] yo no puedo desairar la cena que me has ofrecido" (Benavente, 1981: 183). Con esta inversión semántica, el Desterrado introduce el espíritu de inconformidad con el comportamiento del hostelero. El Desterrado no solo rechaza el banquete de gala sino también la postura ideológica de su supuesto anfitrión. La cena se vuelve una metáfora de la intriga y la codicia de las que el recién llegado se aleja.

Los acercamientos teóricos a la ironía de Booth y Roster comparten el mismo denominador común: la contradicción entre lo dicho y lo hecho. Sin embargo, estas teorías se diferencian por la presencia del despecho que se manifiesta en la visión de Roster. Este sentimiento se traslada de la teoría a la representación dramática y enfatiza la diferencia entre los estados de ánimo de los personajes. El hostelero manifiesta satisfacción con su estado social, mientras el Desterrado permanece amargado por el injusto destierro y la fría recepción en la hostelería.

La satisfacción y la amargura desempeñan papeles clave en la trama dramática. La primera tiende hacia el conservadurismo y la segunda hacia la rebelión. De tal suerte que el hostelero y el Desterrado se vuelven representantes de dos capas sociales y de sus respectivas tendencias ideológicas. El primero representa a los que poseen riquezas y desean conservarlas a través del statu quo y el segundo encarna a los de recursos menores que buscan la transformación de la ciudad a través de la rebelión.

\section{PREDICCIONES Y EVALUACIONES SOCIOECONÓMICAS}

El Desterrado, Arlequín y los mozos prevén una caída catastrófica de la ciudad. Algunos describen el acontecimiento con jocosidad, otros con seriedad. Mientras Arlequín lo anticipa con optimismo, los mozos lo presienten con pesimismo. Los contrastes entre sus perspectivas consuman 
una imagen polivalente de la caída de la ciudad basándose en la comicidad y el realismo. Las visiones opuestas permiten una visión compuesta de diversos principios éticos.

El Desterrado asume la postura profética y predice el futuro de los ciudadanos acaudalados: "Por lucrarse hoy, empobrecerán mañana" (Benavente, 1981: 166). Su presagio de la caída de algunas personas pudientes surge de la observación de los hechos sociales y se fundamenta en varias teorías sobre la ética.

Desde que Soren Kierkegaard introdujo la preponderancia del "yo" existencialista en sus contemplaciones religiosas (Kierkegaard, 2006: 105; 2008: 82-97), se han desarrollado distintas teorías filosóficas con el enfoque individualista ${ }^{1}$. El egoísmo moral o el egoísmo hedonístico de Henry Sidgwick es un ejemplo de este desarrollo que propone una teoría moral fundamentada en el interés de uno mismo (Sidgwick, 1874: 107-110). Desde esta perspectiva, el individuo actúa considerando exclusivamente su provecho personal.

Al referirse a los oportunistas que aprovechan las circunstancias para "lucrarse hoy" (Benavente, 1981: 166), el Desterrado da forma a la teoría del egoísmo hedonístico de Sidgwick. Efectivamente, Pantalón y Polichinela permanecieron enfocados en sus ganancias y pérdidas económicas sin tomar en consideración el bienestar de la población. La muerte, el sufrimiento y la pérdida de la integridad ciudadana ante la invasión de las tropas venecianas pasan desapercibidos por ellos.

El interés personal de Pantalón se transforma en una obsesión. Primero, evoca la pérdida de sus posesiones con lamentaciones descorazonadas y, luego, la codicia lo lleva a la locura. En el cierre de la obra, este permanece tan obsesionado por la pérdida de su hacienda que no se concientiza del peligro inminente que corre su vida:

Voces. - iAl loco! ;Al loco!

Pantalón. —iMi dinero! ¡Mi dinero!

Voces. -iAl loco! ;Al loco!

Desterrado. —iVen aquí, miserable! Impiedad o locura, no clames así por tu dinero... (Benavente, 1981: 243).

\footnotetext{
${ }^{1}$ Aunque en este texto se enfatice la obra filosófica de Kierkegaard, no se olvidan contribuciones y perspectivas sobre la noción del "yo" de los filósofos de la antigüedad como Sócrates, Platón y Aristóteles.
} 
El final de la comedia, marcado por dinámicos cambios socioeconómicos y los gritos de Pantalón, encarna la predicción del Desterrado: "Por lucrarse hoy, empobrecerán mañana" (Benavente, 1981: 166). Esta previsión refleja la crítica del egoísmo moral que el filósofo austríaco Kurt Baier desarrolló (Baier, 1958: 188). Él se refiere a la miopía del egoísta que falla en la búsqueda de su bienestar porque solo ha tomado en consideración las consecuencias inmediatas de sus actos y no las a mediano y largo plazo.

La previsión del Desterrado sobre el porvenir de los rapiñadores presenta su trayectoria en dos etapas: el enriquecimiento desmedido y el fin trágico. Estos resultan derrotados porque han fallado en prever las consecuencias de su comportamiento a largo plazo como lo indica Baier. Se han enriquecido a costa de la ciudad y así han debilitado su infraestructura socioeconómica. Por tanto, la caída de esta en las manos de las fuerzas enemigas arrasa con las posesiones y el bienestar de los ricos. Las ganancias en demasía durante una época se han transformado en un empobrecimiento a largo plazo.

A diferencia del tono grave de la predicción del Desterrado, la obra de Jacinto Benavente cuenta también con augurios cómicos que apuntan en la misma dirección. En su camino al banquete, la carroza del señor Polichinela sufre una volcadura. Lo que ha podido ser un accidente azaroso, que cumple con los criterios cómicos de la comedia española, se vuelve una escena representativa del egoísmo "miope" de Baier: la ganancia inmediata lleva a la pérdida posterior (Baier, 1958: 160).

Ante el aguzado oído y la atenta mirada del público, Crispín separa al señor Polichinela del corrillo para explicarle en confianza la incoherencia de la queja que este le dirige respecto al mantenimiento de los caminos de la ciudad. Así, la obra dramática ofrece un ejemplo de la astucia financiera de Polichinela que primero le proveyó la ganancia y luego ocasionó la pérdida. De nuevo, la moral egoísta de Baier toma cuerpo y, en esta ocasión, el culpable paga su deuda con la ciudad en el lugar mismo donde ha lucrado:

Crispín. - ¿El camino del Puente, decís? Oídme aquí aparte, señor Polichinela. ¿No recordáis que cuando se trató en la Ciudad de abrir ese camino fuisteis vos el que no consintió de ningún modo que se encargaran 
los trabajos a otro que a un muy allegado vuestro, que se hizo pagar muy lindamente..., cuando todos sabemos que por la mitad del coste habia quien abriera mejor camino con ventaja de todo? (Benavente, 1981: 218).

El contexto cómico de la volcadura no augura solamente la caída de un individuo sino también una catástrofe colectiva. A diferencia de la previsión del Desterrado que se fundamenta solamente en los hombres ricos, el camino del Puente es una vía pública por la que circula toda la población en su metafórica trayectoria hacia el fracaso socioeconómico.

La solemnidad de la previsión del Desterrado se combina con la comicidad de la queja de Polichinela para presagiar la caída de la ciudad. El efecto de esta confluencia de tonos opuestos da el color tragicómico a la representación. La tensión dramática y la risa se complementan durante la apreciación de la obra y consolidan la noción de una farsa en la que se conjugan los valores y los estados de ánimo opuestos, así como Preciado la define en La actuación dramática, creativa: la comedia del arte (Preciado, 1990: 112).

A diferencia de la predicción trágica del Desterrado y del mal agüero de la volcadura de la carroza de Polichinela, Arlequín introduce una visión optimista en la escena. Desde su perspectiva, la ruina tendrá una función regeneradora en la reconstrucción de la ciudad.

Arlequín. -Que [los políticos] la gobiernan como se merece: despreciándola. Que por fortuna nos llevarán a la ruina, y entonces empezaremos a ser algo (Benavente, 1981: 171).

La previsión de Arlequín retoma el concepto de opuestos de la ironía de Booth: la ruina económica sirve de base para el renacimiento de la ciudad. En otros términos, lo malo trae algo bueno. Lo que algunos ciudadanos consideran fracaso - como Pantalón y Polichinela—, Arlequín califica de oportunidad. El papel de Arlequín en la Commedia dell'Arte se asocia con bufonadas e ingeniosidades que suelen darse en un ámbito de despreocupación por los protocolos y con un afán de hacer reír (Quezada, 1985: 166). El perfil tradicional de este personaje se reconfirma en La ciudad alegre y confiada. Mientras unos tiemblan por su dinero, Arlequín anticipa con alegría la ruina de la ciudad.

Además de una perspectiva entre inusual y contradictoria sobre el bienestar ciudadano, Arlequín introduce la crítica social en la representación, 
así como Sánchez Estevan lo señala en Jacinto Benavente y su teatro, estudio biográfico crítico (Sánchez, 1954: 121). Según este, además de los aspectos humorísticos, la comedia tiene la capacidad de emitir una crítica social y, por ende, impacta la consciencia colectiva. Siguiendo esta línea de reflexión, el comentario de Arlequín sobre el inadecuado funcionamiento del gobierno da una punzada al público que acogió con cariño a Crispín, el gobernante por excelencia de la ciudad, por su ingeniosidad y la destreza social, aunque su desempeño haya sido marcado con fallas en el ámbito de la ética profesional.

Al atestiguar el ataque contra Crispín, el espectador tiende a defenderlo tácitamente y, en ese impulso, nace una ética propia de esta obra. Se defiende a un protagonista que ha retorcido las leyes y la justicia - como se ha presenciado en Los intereses creados y que Crispín ha confirmado en La ciudad alegre y confiada - para subir a la cima jerárquica. De tal manera que la farsa cuestiona la consciencia de los espectadores que acogen a Crispín y su éxito a costa de la ética que Platón, Aristóteles y Kant basaron en los valores como equidad, justicia, media aurea, deber moral y universalidad, entre otros (Platón, 2007: 195-297; Aristóteles, 2003: 220240; Kant, 2012: 81-82). La obra invierte estos valores éticos a través del apoyo moral brindado a Crispín por el auditorio.

Al lado opuesto de la escala social que ocupa Crispín, se encuentran los mozos de la hostelería. Ellos tienen metas más concretas y mucho más modestas que las que Crispín y Leandro han tenido durante su ascenso a la cima de la jerarquía social. Los mozos empeñan sus vidas y esfuerzos para cubrir sus inmediatas necesidades. Las jornadas arduas y la incertidumbre ante el futuro les han marcado con un realismo pesimista. Lejos de las estipulaciones optimistas del Arlequín sobre la mejora después del acaecimiento de la ruina, su visión se oscurece ante la posibilidad de la inflación que conlleva el abaratamiento de las personas: "cuando todo está más caro, los hombres están más baratos” (Benavente, 1981: 163).

La relación inversa entre los valores de las cosas y de los seres humanos encuentra su lugar en la visión social y realista de la comedia de Jacinto Benavente. Los mozos no destacan personalidades individuales, su función consiste en proveer el panorama de una clase social necesitada. Sus voces y desempeños son uniformes porque su sentir y sus situaciones son iguales. Cuando uno de ellos se expresa sobre su estado social, las demás voces se unen a esta de manera tácita. 
La moraleja de los mozos, "cuando todo está más caro, los hombres están más baratos" (Benavente, 1981: 163), se va desplegando en la marcha de la trama tomando distintas formas. Primero, vertió luz sobre la situación económica de estos y, luego, presagió el destino de los soldados de su ciudad. Cuando la guerra irrumpió, el lema encontró su significado literal en el destino de los militares que se transformaron en carne de cañón. La falta de armas y municiones, ocasionada por la codicia y las malversaciones, les ha dejado a la merced de la muerte y de la humillación.

En la tensión ocasionada por la guerra, nacen los contrastes en los que se fundamenta la ironía de Booth. Por un lado, el espectador atestigua la muerte injustificada de los soldados; y por el otro, Arlequín da un toque burlón al evento: "Con eso nos dirán que ha sido una defensa heroica" (Benavente, 1981: 163). La alternancia entre lo trágico y lo cómico cuestiona los valores humanos y consolida la naturaleza tragicómica de la farsa.

Los comentarios de Arlequín han servido de puntos contrastantes respecto a voces y situaciones serias sobre el destino de la ciudad. Dependiendo del momento de la representación, estos fueron teñidos de burla, malicia e incluso del realismo. Estos tonos se conjugaron con la comicidad de la obra y la realidad del público.

Algunos eventos descritos por Arlequín, que adquirieron una tonalidad chusca en la representación, han acaecido en guerras reales y permanecido en la memoria colectiva. De tal suerte que la representación teatral mantuvo un vínculo estrecho con la realidad. Por ejemplo, la reventazón de un cañón — particularmente de uno de mala calidad- ha sido causa de muerte en diversos conflictos bélicos. Basándose en este suceso real, Arlequín encuentra un aspecto positivo en el hundimiento de un barco de la ciudad por el peligro que sus cañones representan para ellos mismos: "Por dicha nuestra, con ella [la nave] se hundirán sus seis cañones, de los cuales nadie se atreve a disparar con cinco, después que reventó el primero con que fue a dispararse" (Benavente, 1981: 163).

Los acontecimientos reales y su subyacente crítica social, basada en el manejo inapropiado de las finanzas del ejército, se filtran en los comentarios agudos de Arlequín y cunden en el auditorio. La risa que provocan se fundamenta en el desdén por la imperfección de la humanidad y en la alegría de expresar lo que a menudo resulta solapado en las narraciones oficiales de diversos acontecimientos. Así, la jocosidad y 
la crítica social se unen en las predicciones y evaluaciones sociales de Arlequín (Llovet, 1966: 112-117; Gallud, 2011: 89-96).

\section{LA MUERTE}

En su obra El malestar en la cultura, Sigmund Freud retoma los mitos y las creencias relacionados con los dioses de la Antigua Grecia, Eros y Tánatos, para profundizar en el estudio sobre la relación entre la vida y la muerte (Freud, 2015: 111-114). En la antigüedad, Eros era el dios del amor (Garibay, 2011: 237-239), pero Freud le adjudicó un valor más abarcador y lo convirtió en un símbolo de la vida; mientras Tánatos permaneció anclado en el dominio de la muerte. En el pensamiento freudiano, Eros tiende hacia Tánatos. En otros términos, la vida tiene el propósito de llegar a la muerte y, cuando esto sucede, la muerte pone fin a la vida. En La ciudad alegre y confiada, el proceso resulta invertido. Crispín y el Desterrado están convencidos que la muerte purificará y renovará la vida.

Desde el punto de vista teórico de Booth, la vida y la muerte adquieren un sentido irónico en esta obra de Benavente. No solo Crispín y Leandro han predicho que la muerte no acabará con la vida y el amor, sino que los redimirá y los eternizará. Efectivamente, la muerte sublimó el amor que Leandro y Silvia trabaron en Los intereses creados y los redimió de las bajezas como la infidelidad, la mentira y el abandono que Leandro ha adquirido en La ciudad alegre y confiada. La muerte se volvió la herramienta principal en la transgresión de las imperfecciones y en la sublimación del amor.

Al examinar la trayectoria afectiva de Leandro, el espectador identifica tres fases principales. La primera se revela en Los intereses creados en forma del enamoramiento, la segunda se manifiesta en La ciudad alegre y confiada a través del desamor y la tercera desemboca en la muerte de Leandro en la última obra.

Después de la boda, el amor por Silvia se desvaneció y Leandro se volvió un mentiroso en persecución de una bailarina exótica. El hechizo amoroso se esfumó y Leandro cayó en la deshonra pública, la ciudad perdió su modelo del amor ideal que Leandro y Silvia encarnaban.

La caída de Leandro en la estima se manifestó en el auditorio en forma de sonrisas y risas. Así, como Ismael Sánchez lo indica en Jacinto Benavente y su teatro, estudio biográfico crítico (Sánchez, 1954: 82-83), la 
comedia de Jacinto Benavente abunda en escenas jocosas y, en el diálogo citado abajo, la comicidad burlesca surge del intercambio entre Leandro y su confidente Colombina:

Leandro. - [...] doña Sirena, ¿no me dirás hasta cuándo se burlará de mí Girasol?

Colombina. - Decid hasta cuánto, y nos entenderemos.

Leandro. -Ponga ella misma el precio (Benavente, 1981: 184).

Avezada en asuntos amorosos, doña Colombina efectuó un "giro" - como si se inspirara en el nombre de Girasol— con el término "cuándo", de la pregunta de Leandro, y lo sustituyó con "cuánto". Ella dio seguimiento al tema de la "burla", que Leandro introdujo, suplantando la clásica noción de tiempo que separa a los enamorados con una potencial transacción económica.

Así como las transacciones económicas han deshonrado al hostelero, Pantalón y Polichinela, el impulso de Leandro hacia Girasol ha perdido todo cariz romántico por el uso de la negociación monetaria (Núñez, 2018: 71-73). La desvaloración de este amor resulta definitiva y ningún recurso dramático puede reponer lo perdido, con excepción del fallecimiento. El anuncio de la muerte de Leandro impone un silencio respetuoso en el auditorio y el ritmo burlesco de la obra da paso a la solemnidad.

La desaparición del protagonista provoca un enfrentamiento entre Silvia y Girasol que lo han conocido desde dos perspectivas distintas: la de la esposa y la de la amante. En el momento fatídico, ellas pasaron por alto la infidelidad y la falta del collarín de diamantes prometido para sumirse en el dolor ocasionado por la muerte de Leandro. Incluso, Silvia manifiesta un impulso de agredir a Girasol cuya presencia "ofende su dolor" (Benavente, 1981: 235). Su adversidad representa la sublimación de la imagen de Leandro por la muerte y la renovada admiración por su persona.

Solo al traspasar el umbral del más allá, Leandro llega a gozar de nuevo de elogios. Contrariamente al conflicto mitológico entre los dioses Eros y Tánatos, la muerte purificó el amor de Leandro y lo volvió eterno:

Crispín. - [...] Quise ser yo quien llevara a Silvia a rezar ante él... Yo fui testigo de su primer beso de amor, cuando su corazón lleno de vida decía: "Para siempre"... Ahora... será el último beso el que dirá.... "Ya nunca”, que es también para siempre. El amor solo sabe decir palabras de 
eternidad... (Benavente, 1981: 235).

Además de absolver los pecados y de soslayar las debilidades de Leandro, la muerte tiene el don de salvar el alma de la ciudad: "Esa alma es la que importa salvar; la salvaremos" (Benavente, 1981: 222). La salvación colectiva se encamina por dos vías distintas en La ciudad alegre y confiada. Por un lado, la muerte inicia su proceso de purificación a través de un individuo y se extiende a las masas y, por el otro, impacta las masas desde el inicio.

En el esquema de purificación a través de un individuo, Crispín tuvo el privilegio de encarnar el papel de chivo expiatorio cuya muerte llevó a la redención de la ciudadanía. La capacidad de desplegar su poder purificador sobre el pueblo se fundamentó en el estatus socioeconómico que Crispín adquirió a lo largo de sus hazañas. Su trayectoria ascendente lo posicionó en la cúspide social en la que no encarnó solo el poder sino también la maña y la culpabilidad del pueblo que gobernaba.

En su obra Historias y estereotipos, Robyn Quin y Barrie McMahon concluyen que el héroe se vuelve representante de los ideales y de las características de un pueblo (Quin y McMahon, 1997: 128). Siguiendo este paradigma, Crispín se empapa de la naturaleza y de los ideales de su gente para volverse su representante y así libera a la población de sus pecados a través de un acto de inmolación.

En su comportamiento, Crispín ha manifestado una contradicción propia de la ironía de Booth. En Los intereses creados, este desplegó sus artificios para manipular a los acreedores, las leyes y al señor Polichinela para salvarse y proveer un futuro próspero para él mismo y Leandro. En La ciudad alegre y confiada, este perseguidor de la vida y del éxito ha llegado al pináculo del poder y - como si no hubiera más espacio dramático para su ascenso- se volteó contra él mismo en un acto de autodestrucción.

Al orquestar su caída, Crispín decide llevarse consigo a los prójimos. Así, escenifica el despliegue de una inmolación individual que se vuelve colectiva. Su mente se liberó de prejuicios y pasó por alto riñas anteriores para incluir en el cuadro de "prójimos" a los adversarios - como Polichinela y Pantalón — al igual que a su amigo Leandro y al enamorado de su hija, entre otros. Contrastando con la tonalidad airosa de Los intereses creados, Crispín crea un ambiente de fraternidad oscura que entrega la ciudad a la muerte: 
Ahora ambiciono la grandeza de la Ciudad; por conseguirla sacrificaré mis riquezas, mi vida ..., por de contado os sacrificaré a vosotros [...] que hasta el fin hemos de estar unidos, como cómplices de un mismo crimen (Benavente, 1981: 220).

En el cierre de la obra, las palabras ceden el lugar a la actuación y la farsa clásica retoma sus derechos. En un caos apocalíptico, se suceden las persecuciones, rumores macabros, gritos y la muerte. Todos los artefactos dramáticos, visuales y auditivos, señalan la desviación de la trama de la paz precaria de la primera parte de La ciudad alegre y confiada para tomar un rumbo anárquico. La maraña del desorden y de la confusión, tejida por el pánico colectivo, no es más que la materialización del plan de Crispín, el autor intelectual de la trama y del drama.

La metodología del sacrificio de Crispín se basa en el egocentrismo tal y como Jean Piaget la describió en La Psicología de la Inteligencia (Piaget, 1973: 63-64). Crispín es a la vez el autor intelectual de la intriga, su ejecutor y la víctima de la misma. También el método egocéntrico ha sido empleado por Crispín en Los intereses creados, pero con un propósito contrario: su salvación y la del prójimo. En ambas obras, el denominador común ha sido el individualismo de Crispín que le ha otorgado el papel protagónico por excelencia.

A diferencia de Crispín, el Desterrado no intentó desempeñar el papel protagónico ni contempló la posibilidad de que alguna otra persona lo haga. Su pensamiento tomó dimensiones colectivas, concibió la defensa de la ciudad como un deber patriótico a sabiendas que llevaba a una catástrofe humanitaria. Guiado por la noción de responsabilidad compartida y del pecado colectivo, optó por el sacrificio en masa sin ningún liderazgo en particular: "[La guerra] es enviar a la muerte a los soldados, al pueblo; es destruir la Ciudad" (Benavente, 1981: 222). Su ideología del sacrificio uniformizó a todos los ciudadanos y los privó del liderazgo individual. Incluso, su hijo Lauro se volvió uno de esos soldados anónimos que el Desterrado precipitó a la muerte.

La idea de la regeneración de la ciudad a través de la muerte une a Crispín y al Desterrado. Su complementariedad se manifestó en el momento en que este adoptó el uso de la mentira para lanzar al pueblo a una lucha suicida: "Sí; le hablaré [al pueblo] desgarrado mi corazón, 
porque he de mentirle, he de mentirle por primera vez en mi vida. Hablaré de triunfos, de glorias... Y sabemos lo que será esa guerra..." (Benavente, 1981: 222). Así como fueron unidos por la noción de la expiación a través de la muerte, adoptan la mentira como método de implementación de su plan y así consolidan su unión.

La noción freudiana que se basa en la conclusión de la vida con la llegada de la muerte contrasta con la ideología de Crispín y del Desterrado. Ellos cuentan con la muerte para vigorizar y purificar la vida. Este ímpetu redentor de la muerte se manifestó también en la renovación del amor de Leandro y Silvia. En La ciudad alegre y confiada, la muerte desempeña el papel regenerador de la vida ética y del amor.

\section{CONCLUSIÓN}

Ramón Pérez de Ayala y Christopher Soufas han criticado la obra dramática de Jacinto Benavente por su abundancia de diálogos que, según ellos, la asemeja más a una obra literaria que a una representación dramática. Ramón Pérez la considera "antiteatral", mientras Christopher Soufas la cataloga de "poorly developed sense of theatricality" (Pérez de Ayala, 1966: 291; Soufas, 2000: 151). Sus comentarios se fundamentan en la necesidad de dar prioridad a la actuación y a la significación del cuerpo del actor en el escenario a costa del diálogo, del monólogo y de didascalias. Esta prerrogativa dramática fue llevada al mundo teatral por Bertolt Brecht y Antonin Artaud a través de sus publicaciones canónicas, Brecht on Theater (Brecht, 1964) y Le Théâtre et son double (Artaud, 1938), y sus puestas en escena de numerosas obras.

Aunque la postura de Ramón Pérez de Ayala y Christopher Soufas sea bien fundamentada en la teoría y la apreciación de La ciudad alegre y confiada, hay que tomar en cuenta que la trama de esta obra se fundamenta en dos distintas y complementarias etapas. La primera toma forma de un preámbulo en el que se gesta la idea de un cambio socioeconómico e ideológico que fue promovido por la injusticia social, la codicia y la vulnerabilidad tanto ética como militar. Mientras el caos se cierne sobre la ciudad, se abre un espacio de intercambio de ideas y predicciones sobre un cataclismo y el consecuente renuevo de la ciudad. En esta etapa, el uso del lenguaje fue necesario para introducir distintas perspectivas ideológicas y permitir algunos enfrentamientos entre estas. 
Asimismo, el lenguaje dio a conocer acontecimientos cuya representación hubiera requerido un uso excesivo de tiempo y de distintos escenarios, como por ejemplo la reventazón del cañón de un buque de guerra. También los diálogos permitieron a personajes manifestar distintos estados de ánimo que fluctuaron desde la amargura hasta la comicidad. El refinado uso lingüístico de estos recreó el ambiente social e ideológico y, así, preparó el escenario para la segunda etapa.

En esta, la tensión acumulada produjo una explosión socioeconómica que trastornó el orden preestablecido. Ante el auditorio, se desplegó un baño de sangre de los ciudadanos, el saqueo colectivo y el levantamiento del pueblo contra sus gobernantes. La actuación y sus manifestaciones verbales recrearon el ámbito de la comedia española que se nutre del dinamismo de la Commedia dell'Arte.

En el cierre de la obra, los acontecimientos trágicos se combinaron con los de la solemnidad dramática del Desterrado que usó el cuerpo de su hijo para hincar la bandera de purificación colectiva. Asimismo, en el desconcierto general de los personajes, se perfila la figura de Pantalón que clama por su dinero sin prestar oídos a los asesinos que lo persiguen para quitarle la vida. El cierre de esta obra resaltó la actuación y la presencia escénica de los personajes que Brecht y Artaud definieron como criterios insoslayables de una representación teatral.

La primera parte de la obra ha necesitado de una paz precaria y de un intercambio ideológico para dar paso al bullicio final. Los calificativos de la ciudad que se destacaron en el título de la obra, "alegre y confiada", fueron sustituidos dramáticamente en el cierre por la saña y la destrucción. Este contraste se reflejó en la forma de representación en la que la primera fase se nutrió de un lenguaje anunciador del cambio socioeconómico, mientras la segunda desplegó el vigor de la destrucción con todos sus atributos dramáticos.

\section{REFERENCIAS BIBLIOGRÁGICAS}

ARISTÓTELES. (2003). Ética nicomáquea. Madrid: Gredos. ARTAUD, A. (1938). Le Théâtre et son double. París: Gallimard. BAIER, K. (1958). The moral Point of View: a rational basis of Ethics. New York: Cornell University Press. 
BALLESTEROS DORADO, A. (2003). Espacios del drama romántico español. Madrid: CSIC.

BENAVENTE, J. (1907). Los intereses creados: comedia de polichinelas, en dos actos, tres cuadros y un prólogo. Madrid: Sociedad de Autores Españoles.

(1981). La ciudad alegre y confiada, Comedias escogidas. Madrid: Aguilar.

BOOTH, W. (1974). Rhetoric of Irony. Chicago: University of Chicago Press.

BRECHT, B. (1964). Brecht on Theatre. New York: Hill and Wang.

CRITCHLEY, S. (2002). On Humour. New York: Routledge.

FREUD, S. (2015). El malestar en la cultura. Buenos Aires: Amorrortu.

GALLUD JARDIEL, E. (2011). "Jacinto Benavente y su visión satírica del teatro por dentro". Anagnórisis 3, http://www.anagnorisis.es/ pdfs/gallud_jardiel.pdf [22/10/2019].

GARIBAY K., A. (2011). Mitología griega: dioses y héroes. México: Editorial Porrúa.

KANT, I. (2012). Crítica de la razón pura. Valencia: Diálogo.

KIERKEGAARD, S. (1968). The Concept of Irony, with constant references to Socrates. Bloomington: Indiana University Press.

(2006). O lo uno o lo otro, un fragmento de vida I. Madrid: Trotta. (2008). Temor y temblor. Buenos Aires: Editorial Losada.

LLOVET, E. (1966). "Jacinto Benavente y su circunstancia literaria y social". Cuadernos Hispanoamericanos 204, 519-526.

MONNER SANS, J. (1966). "El centenario de Jacinto Benavente". Ediciones Revista Atenea 12, 86-114.

MONTERO ALFONSO, J. (1967). Jacinto Benavente. Su vida y su teatro. Madrid: Sucesores de Rivadeneira.

NÚÑEZ REY, C. (2018). "El ensayismo de Carmen de Burgos, Colombina, en defensa de la igualdad de la mujer". Estudios Románicos 27, 6174.

OLIVA, C. (2002). Teatro español del siglo XX. Madrid: Síntesis.

PÉREZ DE AYALA, R. (1966). Las máscaras. Obras completas III. Madrid: Aguilar.

PIAGET, J. (1973). La Psicología de la Inteligencia. Barcelona: Crítica. PLATÓN (2007). "Sócrates". Diálogos, volumen II, 192-199. México: Editores Mexicanos Unidos. 
PRECIADO, J. (1990). La actuación dramática, creativa: la Comedia del arte. México: Noriega.

QUEZADA, A. (1985). La comedia del arte. México: Fondo de Cultura Económica.

QUIN, R. y McMAHON, B. (1997). Historias y estereotipos. Madrid: Ediciones de la Torre.

ROSTER, P. (1978). La ironía como método de análisis literario: la poesía de Salvador Novo. Madrid: Gredos.

SÁNCHEZ ESTEVAN, I. (1954). Jacinto Benavente y su teatro, estudio biográfico crítico. Barcelona: Ariel.

SIDGWICK, H. (1874). The methods of ethics. Londres: MacMillan.

SOUFAS, CH. (2000). "Benavente and the Spanish Discourse on Theater". Hispanic Review 68.2, 148-159.

STARKEY, W. (1924). Jacinto Benavente. Londres: Oxford Press.

Recibido el 24 de febrero de 2020.

Aceptado el 9 de mayo de 2020. 